\title{
Wide-spread sensitization in inflammatory pain model is regulated by neuronal activities in the amygdala
}

Mariko Sugimoto, Yukari Takahashi, Yae K Sugimura, Yuta Miyazawa, Ayako M Watabe, Fusao Kato Jikei Univ Sch of Med, Center for Neuroscience of Pain, Dept of Neuroscience, Tokyo, Japan

\section{Backgrounds}

Allodynia and hypersensitivity are the hallmarks of chronic pain. They involve changes in the activity of central nervous system.

The central amygdala $(\mathrm{CeA})$ receives nociceptive information directory from the spinal /medullary dorsal horn, sends information to the periaqueductal grey (PAG), and lies upstream to the "descending pain modulatory system".

The $\mathrm{CeA}$ is a brain nucleus that shows robust plastic changes in various pain models and patients with chronic pain
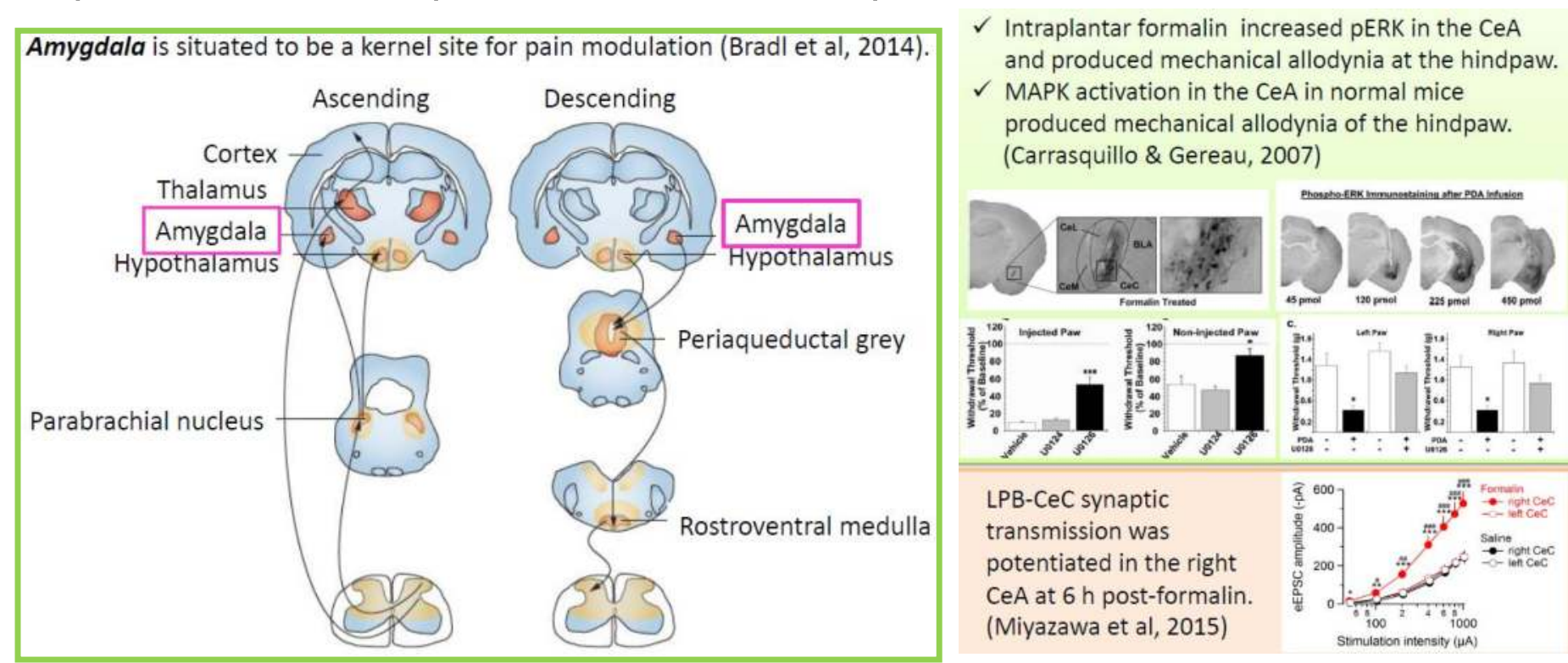

\section{Aims}

1. To evaluate wide-spread sensitization in a rodent pain model with long-lasting inflammation in the region with trigeminal nerve innervation.

2. To examine possible involvement of the $\mathrm{CeA}$ in the establishment of wide-spread sensitization.

\section{Approaches}

We used "latent formalin inflammation (LFI) model" in rats, by injecting $5 \%$ formalin into the left upper lip.

As an index of wide-spread sensitization, we measured mechanical paw withdrawal threshold (PWT) in the hind limb using von Frey filaments.

The activity of the CeA neurons was manipulated in this model, using:

1) pharmacological blockade of calcitonin gene-related peptide (CGRP) receptors by local microinjection of the antagonist into the $\mathrm{CeA}$, and

2) chemogenetic inhibition of the GABAergic neuronal activity with clozapine-N-oxide (CNO, i.p.) in the VGAT-Cre rats expressing the Designer Receptors Exclusively Activated by Designer Drugs (DREADD) in the CeA.

\section{Sensitization in the bilateral hind limb in $1.5-72 \mathrm{~h}$ after formalin injection in orofacial LFI model}
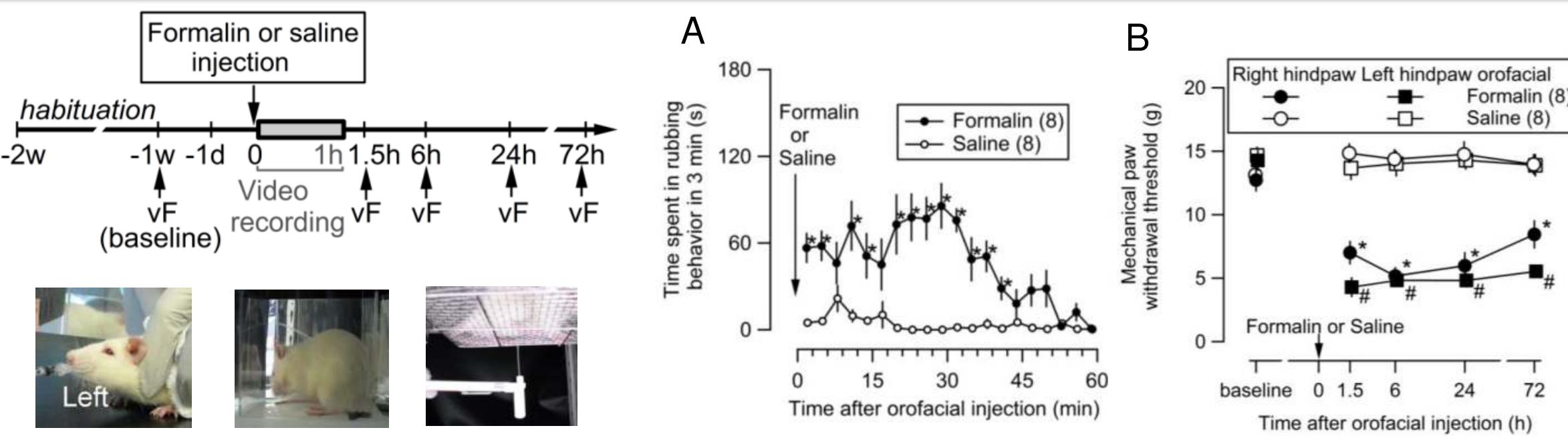

A. Acute nocifensive face scrubbing behaviors lasted for $<1 \mathrm{~h}$ post-formalin $\left({ }^{*} \mathrm{P}<0.05, t\right.$-test $)$.

B. Mechanical paw withdrawal threshold in the bilateral hind limb of the orofacial LFI. Manifest lowering of PWT (i.e., hypersensitivity) started as early as $1.5 \mathrm{~h}$ lasting up to $72 \mathrm{~h}$ post-formalin ( ${ }^{*} \mathrm{P}$ $<0.05$, $t$-test: formalin vs control; \#P $<0.05$, paired $t$-test; compared with baseline).

2 Blocakde of CGRP receptors in the CeA transiently mitigated the ectopic allodynia.

$\begin{array}{ll}\begin{array}{c}\text { Implantation } \\ \text { of guide cannula }\end{array} & \begin{array}{l}\text { Formalin } \\ \text { or saline }\end{array}\end{array}$

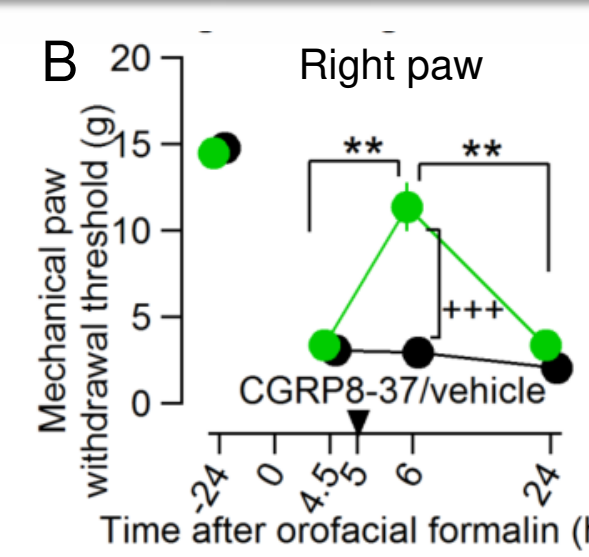

Time after orofacial formalin

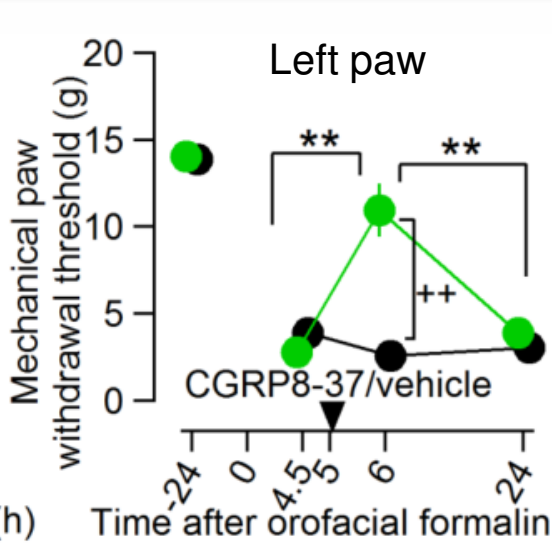

B. Microinjection of a CGRP receptor antagonist, $\mathrm{CGRP}_{8-37}$, in the right $\mathrm{CeA}$ at $5 \mathrm{~h}$ after formalin injection transiently ameliorated the ectopic allodynia. $\left({ }^{* *} \mathrm{P}<0.01\right.$, paired $t$ test: $4.5 \mathrm{~h}$ vs $6 \mathrm{~h}$, or $6 \mathrm{~h}$ vs $24 \mathrm{~h}$ in the CGRP $_{8-37}$ treated group; +++ $\mathrm{P}<0.001,++\mathrm{P}$ $<0.01$, $t$-test: CGRP $_{8-37}$ vs vehicle.)
3 In the rats with Gi-DREADD in the CeA GABAergic neurons, CNO (a DREADD agonist) significantly rescued the decreased PWT in the formalin group.
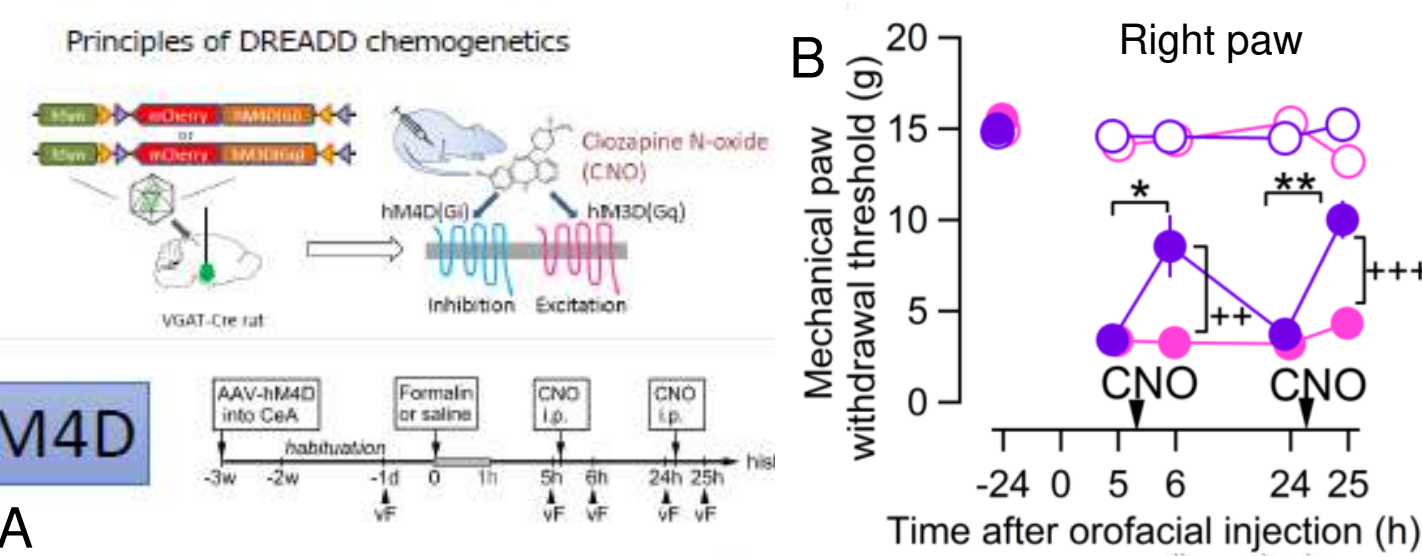$$
\text { B1 }
$$
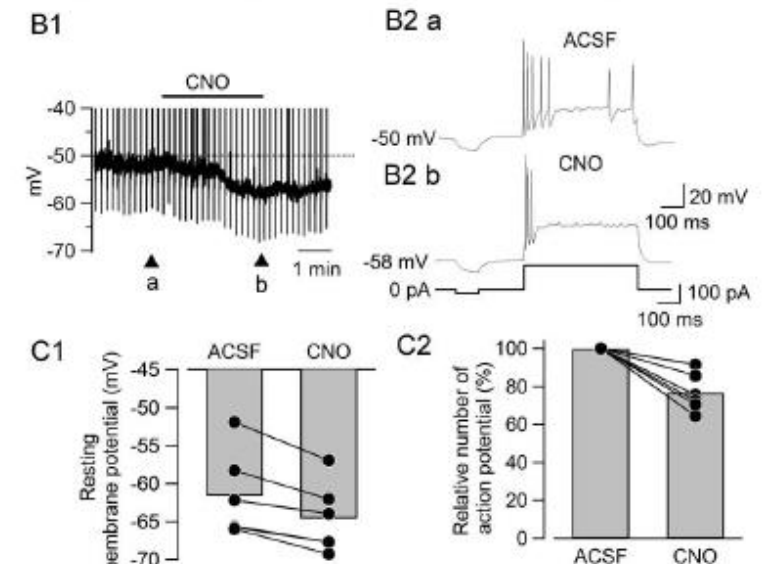

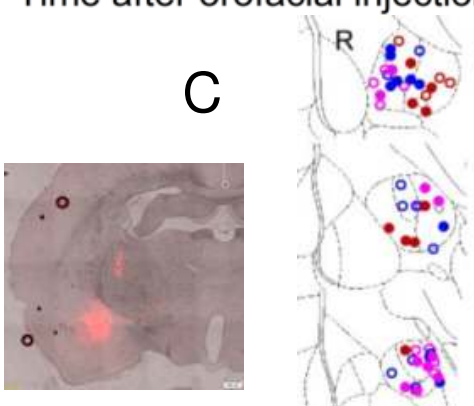

A. $\mathrm{CNO}(5 \mu \mathrm{M})$ hyperpolarized $\mathrm{CeA}$ GABAergic neurons expressing hM4DmCherry in acute brain slices.

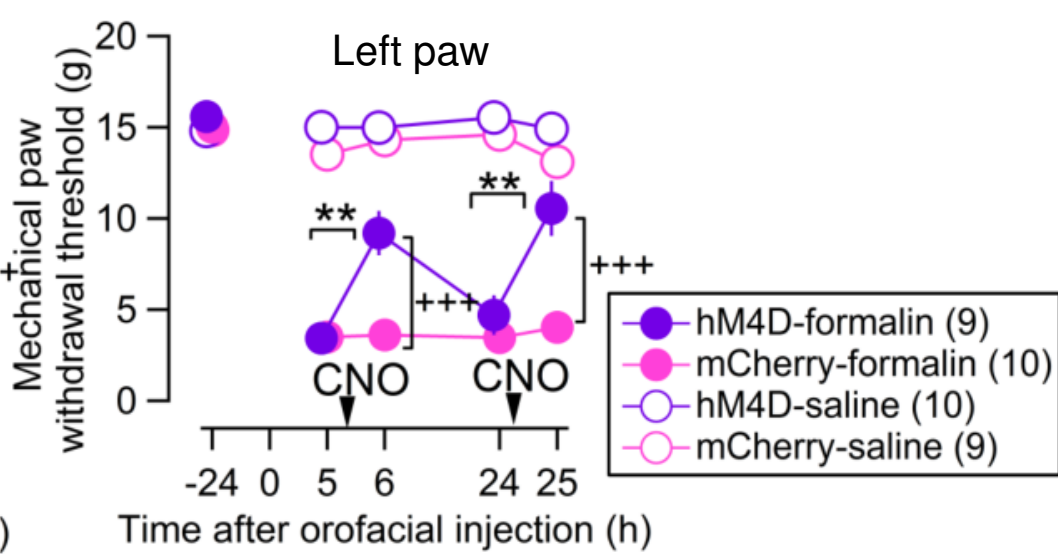

B. The DREADD agonist-induced inhibition of the GABAergic neuronal activity in the CeA transiently ameliorated the ectopic allodynia.

$\left({ }^{*} \mathrm{P}<0.05,{ }^{*} \mathrm{P}<0.01\right.$, paired $t$-test: before vs after CNO; ++P $<0.01$, +++P $<0.001$, 1 way ANOVA, post-hoc Gabriel )

C. Sites of the AAV injection plotted in the brain maps of Paxinos and

Watson.

\section{Conclusions}

- The allodynia and hypersensitivity do not necessarily result from the injury at the site of expression, but rather reflect changes in the brain structures, such as the $\mathrm{CeA}$, controlling the sensitivity of the sensory system.

- The activation of CeA neurons by persistent peripheral inflammation would be a cause for the "ectopic sensitization".

- The CeA would be an important target for the chronic pain treatment not only for the emotional complication but rather in the cases in which the cerebral control plays greater roles in its etiology.

\section{References \\ Hans \& Neugebauer J Neurosci, 2005. \\ Carrasquillo \& Gereau, J Neurosci 2007. \\ No COI to disclose concerning this study.}

